\title{
Emergência e transformações ocorridas nas políticas e práticas de reconhecimento de adquiridos experienciais (RAE) em Portugal (1999-2017)
}

\author{
Rosanna Barros
}

\section{Resumo}

Neste artigo analisam-se as três políticas portuguesas para a educação e formação de adultos (EFA) que assentaram a sua lógica no reconhecimento de adquiridos experiencias (RAE), nomeadamente: o Programa de Ação S@ber+: Programa para o Desenvolvimento e Expansão da Educação e Formação de Adultos (1999-2005), o Programa Iniciativa Novas Oportunidades (2006-2012) e o Programa Qualifica (desde 2016). Refletindo sobre os enquadramentos e contextos, com base nos dados e resultados de duas investigações científicas: uma etnografia crítica conduzida entre 2004 e 2005; e uma investigação-ação em curso desde 2016; o objetivo foi apontar as principais caraterísticas e tensões inerentes a quinze anos de transformações da agenda deste sector $e$ das práticas intrínsecas ao Reconhecimento, Validação e Certificação de Competências (RVCC). A principal conclusão que se retira da analise é que o RAE, tal como tem existido em Portugal desde 2001, e não obstante as contradições mapeadas neste texto, representa uma prática que tem contribuído para a promoção de equidade e igualdade no usufruto do direito à educação por parte dos adultos vulneráveis (em termos de qualificações).

Palavras-chave:

Educação e Formação de Adultos (EFA); Reconhecimento de Adquiridos Experienciais (RAE); Processo de Reconhecimento, Validação e Certificação de Competências (RVCC). 


\title{
Emergence and transformations in the policy and practice of Recognition of Prior learning in Portugal (1999-2017)
}

\begin{abstract}
This article examines the three Portuguese policies for education and training of adults who settled their logic in the recognition of prior learning, namely: the Action Program Knowing+: program for the development and expansion of education and training of Adults (1999-2005), the New Opportunities Initiative Program (2006-2012) and the Program Qualifies (from 2016). Reflecting on the contexts and frameworks, based on the data and results of two scientific research: a critical Ethnography conducted between 2004 and 2005; and a research-action underway since 2016; the objective was to point out the main features and tensions inherent in fifteen years of transformations of this sector's agenda and practices intrinsic to the recognition, validation and certification of competences. The main conclusion of the analysis is that the recognition of acquired experience, as has existed in Portugal since 2001, and notwithstanding the contradictions mapped in this text, is a practice that has contributed to the promotion of equity and equality in the enjoyment of the right to education by vulnerable adults (in terms of qualifications).
\end{abstract}

Keywords: Adult education and training; Recognition of prior learning; Process of recognition, validation and certification of competences.

\section{Émergence et changements dans la politique et la pratique de la reconnais- sance, validation et certification des acquis expérientielles au Portugal (1999- 2017)}

Résumé: Cet article examine les trois politiques portugais pour l'éducation et la formation des adultes qui se sont établis avec la logique de la reconnaissance des expériences acquises, à savoir : du Programme d'Action Connaitre+ : Programme pour le Développement et l'Expansion de l'Éducation et Formation des Adultes (1999-2005), le Programme Nouvelles Possibilités (2006-2012) et le Programme Qualifier (à partir de 2016). On présente des réflexions sur les contextes et les cadres, basé sur les données et les résultats des deux recherches scientifiques : une ethnographie critique réalisée entre 2004 et 2005; et une recherche-action en cours depuis 2016; l'objectif était de rappeler les principales caractéristiques et les tensions inhérentes à quinze ans de transformations de l'ordre du jour de ce secteur et les pratiques inhérentes à la reconnaissance, la validation et la certification des compétences. La principale conclusion de l'analyse se retire du fait qui la reconnaissance de l'expérience acquise, tel qu'il a existé au Portugal depuis 2001 et malgré les contradictions présenté dans ce texte, est une pratique qui a contribué à la promotion de l'équité et l'égalité dans la jouissance du droit à l'éducation des adultes vulnérables (en termes de qualifications)

Mots-clés: Éducation et Formation des Adultes; Reconnaissance des acquis expérientielles; Processus de Reconnaissance, Validation et Certification des Compétences.

\section{Aparición y cambios en la política y la práctica de reconocimiento de la expe- riencia adquirida en Portugal (1999-2017)}

Resumen: En este artículo se analizan las tres políticas portuguesas de educación y formación de personas adultas que se basan en el reconocimiento de los adquiridos de la experiencia: el Programa Acción Saber+: programa para el desarrollo y expansión de la educación de adultos y formación (1999-2005), el Programa Nuevas Oportunidades (2006-2012), y el Programa Cualifica (desde 2016). La reflexión sobre los contextos y marcos se basa en los datos e resultados de dos investigaciones científicas: una etnografía crítica (2004 e 2005), y una investigación-acción (en curso desde 2016). El objetivo ha sido señalar las principales características y tensiones ocurridas en quince años de prácticas de reconocimiento de los adquiridos de la experiencia. Nuestra principal conclusión es que el reconocimiento de los adquiridos de la experiencia (RVCC) portugués ha contribuido para la equidad y la igualdad del usufructo del derecho a la educación por parte de las personas adultas más vulnerables (en términos de cualificaciones).

Palabras-clave: Educación y Formación de personas adultas; Reconocimiento de Adquiridos Experienciales; Proceso de Reconocimiento, validación y certificación de competencias. 


\section{Considerações prévias}

No campo da EFA o RAE aparece associado a dois contextos históricos particulares do pós-guerra, em que pressões de grupos de interesses específicos (soldados norte-americanos e feministas canadianas) garantiriam o reconhecimento das experiências vividas fora do percurso escolar como forma de assegurar o acesso ao ensino superior tomando em linha de conta a experiência prévia de quem aprende, predominando para este fim a metodologia do balanço de competências que propõe uma lógica alternativa ao diagnóstico de necessidades de formação (Barros, 2013a).

Desde então o RAE conheceu diversos processos de expansão e adaptação a contextos variados (Andersson, Fejes, \& Sandberg, 2016). Neste texto, observámos o caso português tecendo considerações quer acerca da sua emergência na agenda política em 1999, quer acerca das transformações ocorridas nas suas políticas e práticas até à atualidade.

Metodologicamente este artigo foi redigido com base nos dados e resultados de duas investigações científicas elaboradas em função de distintos enquadramentos, nomeadamente: i) uma etnografia crítica em educação de adultos, que foi realizada num Centro de Reconhecimento, Validação e Certificação de Competências (CRVCC) na região rural do sul de Portugal, cujo trabalho de campo foi contínuo e efetuado entre 2004 e 2005, e no âmbito do qual foram aplicadas as técnicas da entrevista e da observação direta participante. Esta investigação compreendeu também a análise documental e de discurso e ocorreu no contexto da realização de um doutoramento na Universidade do Minho (Barros, 2009); ii) uma investigação-ação, que se encontra em curso e vem sendo realizada num Centro de Qualificação e Ensino Profissional (CQEP), e agora Centro Qualifica (CQ), na região urbana do sul do país, cujo trabalho de campo foi iniciado em 2016 e se encontra em progresso e no âmbito do qual estão a ser aplicadas as técnicas da entrevista e da observação direta não-participante. Esta investigação decorre no contexto do desenvolvimento de um projeto de investigação internacional financiado pelo Programa Erasmus + (2015-2018: Projeto 479A0AF7447AC35B, EURE.K - Validation des Compétences-clés Européennes).

\section{A emergência de uma política pública assente no RAE - 1999 o ano zero}

Em vésperas da viragem do século, foi criado em Portugal um Grupo de Missão para o Desenvolvimento da Educação e Formação de Adultos (GMEFA), incumbido de lançar um Projeto de Sociedade S@ber +. Entre os seus vários objetivos, estava o de colocar os alicerces de uma nova oferta, que se desejava acessível, flexível e adequada aos adultos pouco escolarizados do contexto nacional. 
Para tal, foi promovida a articulação estratégica com as autarquias, escolas, parceiros sociais e entidades privadas visando a construção experimental e gradual de um sistema de validação formal dos saberes e competências informais (Barros, 2011). A partir das dinâmicas suscitadas pelo GMEFA, iniciou-se efetivamente "a construção de um $3^{\circ}$ sector autónomo - mas complementar do sistema escolar de cursos noturnos e das ações de formação profissional - o sistema EFA, tão desescolarizado quanto possível" (Melo et al, 2001, p. 106). E, desde então, adotou-se uma nova conceptualização do campo, que deixou oficialmente de ser de educação de adultos (EA) para passar a ser de educação e formação de adultos (EFA), entendendo-se por tal:

... o conjunto das intervenções que, pelo reforço e complementaridade sinérgica com as instituições e as iniciativas em curso no domínio da educação e da formação ao longo da vida, se destinam a elevar os níveis educativos e de qualificação da população adulta e a promover o desenvolvimento pessoal, a cidadania ativa e a empregabilidade. (Id., Ibid, p. 11)

O Projeto de Sociedade S@ber +, deu origem, até ao presente, a um conjunto sequencial de três políticas públicas destinadas à educação das pessoas adultas, cujo denominador comum é terem o seu alicerce fundamentado em práticas de RAE. Ora, este artigo debruça-se na análise destas políticas e práticas.

\section{O RAE no Programa de Ação S@ber+: Programa para o Desenvolvimento e Expansão da Educação e Formação de Adultos (1999-2005)}

Com esta política pública o estreito panorama da oferta nacional de EFA, existente à época, diversificou-se e a aposta surgiu orientada para a consolidação de um novo Sistema EFA de estrutura modelar centrado no RVCC, resultado da autoformação da população adulta, tendo-se priorizado a criação das estruturas necessárias para permitir que os adquiridos informais fossem alvo de uma "análise rigorosa e reconhecimento formal, traduzidos numa validação oficial: creditação (outorga de créditos) com equivalência, parcial (dispensa de uma certa parte do percurso de formação) ou total (certificação, obtenção imediata de diploma oficial)" (Melo et al., 2001, p. 33).

Tanto o ano de 2000 como o de 2001 foram marcados, em Portugal, pela entrada em cena da Agência Nacional de Educação e Formação de Adultos (ANEFA), tendo sido promovidas atividades que se destinaram, no essencial, a ir ao encontro da frágil situação educacional da população ativa mediante a "criação de soluções flexíveis que articulem a educação e a formação, através de percursos organizados, a partir de processos de reconhecimento e validação de saberes adquiridos e de sistemas modulares de formação" (ANEFA, 2001, p. 29). A par do Ensino Recorrente de Adultos (ERA), 
básico e secundário, e da Educação Extraescolar (EEE), a estruturação da nova oferta de EFA compreendeu, a partir deste período, as seguintes modalidades: uma oferta de Cursos de Educação e Formação de Adultos (Cursos EFA); uma oferta de Ações S@ ber+; e uma oferta de RVCC. Pelo que, como resultado das políticas públicas efetivadas pela ANEFA, se viria a constatar um alargamento da rede nacional afeta ao sector.

Assim, emergiu, por um lado, o Sistema de RVCC que deu expressão nacional à lógica de RAE e, por outro lado, a construção (Portaria n. 1082-A/2001, DR 206, Série I-B, de 5 de Setembro) de uma Rede de Centros RVCC (vigente, com esta designação, entre 2001 e 2005). Definiu-se, também, a equipa técnica composta, de um lado, pela equipa permanente, a que correspondiam: um Diretor e/ou um Coordenador/Animador Local (quando o Diretor estivesse a tempo parcial); três Profissionais de RVCC; um Administrativo; e um Técnico de Apoio à Gestão Financeira; e, de outro lado, pela equipa eventual, a que correspondiam: quatro (tempo parcial) ou dois (tempo integral) Formadores; e um Avaliador Externo.

Desde então os adultos pouco escolarizados em Portugal passaram a poder inscrever-se nas novas ofertas de EFA disponíveis, sendo o mais característico do Sistema RVCC o seu enquadramento numa estratégica que passou por assumir que "existe em Portugal uma subcertificação" (ANEFA, 2001, p. 39), tendo sido considerado um fator de justiça social "ser dada a oportunidade a todos os cidadãos, e, em particular, aos menos escolarizados e aos ativos empregados e desempregados, de verem reconhecidas e certificadas as competências e conhecimentos que, nos mais variados contextos, foram adquirindo ao longo do seu percurso de vida" (ANEFA, 2001, p. 21).

Toda a criação do Sistema RVCC português regeu-se pelo princípio de que "é possível e necessário valorizar a experiência e as capacidades profissionais, além de pessoais e cívicas, dos adultos para melhorar também o seu nível educacional" (Silva, 2002, p. 73). Neste período fértil de criação dos CRVCC a prioridade foi assegurar o desenvolvimento do essencial dos processos metodológicos inerentes ao Sistema RVCC, ou seja: quer as bases do modelo de organização e intervenção inerente ao processo RVCC; quer os materiais específicos de apoio ao desenvolvimento estrutural e organizacional das práticas (por exemplo, foi elaborado pela ANEFA um kit para o processo RVCC); quer dos diversos instrumentos diretos de apoio para os profissionais de RVCC e para os adultos em processo; quer de dispositivos indiretos de apoio para uma documentação técnica/pedagógica adequada a todos os intervenientes no processo de RVCC; quer da compilação e divulgação de materiais de suporte teórico ao processo de balanço de competências e à construção do Dossier Pessoal (Portefólio) dos adultos.

Ora, o modelo adotado em Portugal para o RAE, desde a sua criação até ao presente, esteve baseado num Referencial ${ }^{1}$ de Competências-chave e em três eixos 
estruturantes de atuação, que são sequencialmente: o eixo de reconhecimento de competências-chave; o eixo da sua validação; e o eixo da sua certificação.

Assim, o eixo de reconhecimento de competências-chave é entendido no contexto nacional como o "processo de identificação pessoal das competências previamente adquiridas no qual se procura proporcionar ao adulto ocasiões de reflexão e avaliação da sua experiência de vida, levando-o ao reconhecimento das suas competências e promovendo a construção de projetos pessoais e profissionais significativos" (ANEFA, 2002, p. 15). Na medida em que o reconhecimento "é promovido numa lógica formativa, de incremento da motivação para aprender" (CNE, 2002, p. 70), parte-se do pressuposto basilar de que o mesmo "constitui um passo extremamente importante na criação da identidade pessoal e social, no desenvolvimento da autoestima e da confiança do indivíduo para progredir em aprendizagem e no desenvolvimento de competências" (id., ibid.). Em termos processuais estipula-se que o reconhecimento de competências "constitui o conjunto das atividades, assentes numa lógica de balanço de competências e histórias de vida, no qual se promovem ocasiões de identificação e avaliação de competências, utilizando, para o efeito, um conjunto diversificado de meios" (ANEFA, 2002, p. 15), sendo, pois, no decorrer das diversas fases e atividades concretas que integram este eixo de intervenção que, como sublinham Correia e Cabete, "o adulto deverá construir, com o apoio do profissional de RVCC e dos formadores das quatro áreas de competências-chave, o seu dossier pessoal, documento onde se encontram todas as evidências documentais das competências de que o adulto é portador" (Correia \& Cabete, 2002, p. 49).

Na sequência deste processo de reconhecimento virá então o segundo eixo estruturante de atuação nos CRVCC, o eixo de validação de competências-chave, concebido como o "ato formal realizado por uma entidade devidamente acreditada que visa a atribuição de uma certificação com equivalência escolar" (ANEFA, 2002, p. 15), isto é, "representa o conjunto de práticas conducentes à atribuição de estatuto oficial e institucional às competências do indivíduo" (CNE, 2002, p. 71). Processualmente a validação de competências faz-se perante um júri de validação (que contava até 2012 com a presença de um avaliador externo ao Centro), cuja missão, como referem Correia e Cabete, "consiste em analisar e avaliar o dossier pessoal apresentado pelo adulto, interpretando a correlação entre todas as evidências aí documentadas e o referencial de competências-chave" (Correia \& Cabete, 2002, p. 50).

Finalmente, a conclusão do processo de RVCC, tal como foi criado em Portugal, envolve o último dos eixos estruturantes referente à certificação das competências-chave. Este eixo é entendido como a "confirmação oficial das competências adquiridas através da formação e/ou da experiência" (ANEFA, 2002, p. 16), e envolve, em termos processuais a "oficialização da validação das competências através do registo na Carteira Pessoal de Competências-chave e, sempre que for caso disso, por decisão 
do Júri de validação, haverá lugar à emissão de Certificados de nível Básico 3, 2 ou 1, equivalentes, para todos os efeitos legais, aos $3^{\circ}, 2^{\circ}$ ou $1^{\circ}$ Ciclos do Ensino Básico" (id., ibid.), sendo a certificação, propriamente dita, "proporcionada por via das Instituições formais do sistema educativo" (CNE, 2002, p. 71). Quando todo o processo de RVCC se encontra concluído nestas três componentes sequenciais de ação, os produtos finais que ficam na posse do adulto-educando, que percorreu este caminho num determinado CRVCC da Rede nacional, são: o Dossier Pessoal ou Portfólio; a Carteira Pessoal de Competências-chave, e o Certificado.

No fundo, todo este processo inerente ao modo de implementação desta nova modalidade educacional para adultos pouco escolarizados, tal como foi introduzida e operacionalizada em Portugal, teve como finalidade "promover a visibilidade destas aprendizagens informais, experienciais, e atribuir-Ihes um 'valor de uso', tanto na esfera educativa como social e profissional" (Pires, 2005, p. 3). Trata-se, com efeito, de fazer assentar por princípio todo o processo de RVCC num axioma basilar da esfera tradicional da EFA, o de que todos os adultos são portadores de um conjunto amplo, e frequentemente invisibilizado, de competências e saberes que adquiriram de múltiplas formas (Barros, 2013b, 2014). Ora, durante este período, o modo como os Profissionais de RVCC encaravam a sua função atravessava esta lógica pedagógica, como estes testemunhos, recolhidos à época traduzem:

...compete-me levar o adulto a consciencializar-se da importância de todos os conhecimentos que possui e seu respetivo valor (...) tenho que assumir um papel de facilitadora, de ajuda na (re)descoberta das suas competências, o que, por vezes, se torna um processo difícil [RE (S) 2. Trabalho de Campo 2004-2005].

... ao longo do meu trajeto de profissional de RVCC, procurei sempre estar atenta à minha prática, por exemplo, o tipo de linguagem que utilizava... era demasiado académica e desajustada à realidade com que me deparava (adultos com baixos níveis de escolaridade). Este foi um dos aspetos que fui alterando [RE (S) 1. Trabalho de Campo 2004-2005].

Nestes moldes o arranque efetivo desta nova oferta partiu do Projeto-piloto que foi implementado em torno de 6 CRVCC em observação. Assim, o processo RVCC estabilizou em alguns momentos estruturantes, designadamente: o atendimento, a informação e o aconselhamento que se conceberam logo à entrada do processo; seguidos da identificação de competências; e possivelmente por formações complementares; em cujo decurso se oferecem informação e aconselhamento; até à validação e certificação (figura 1). 
Figura 1 - Fases do Processo de Reconhecimento de Adquiridos Experienciais num CRVCC

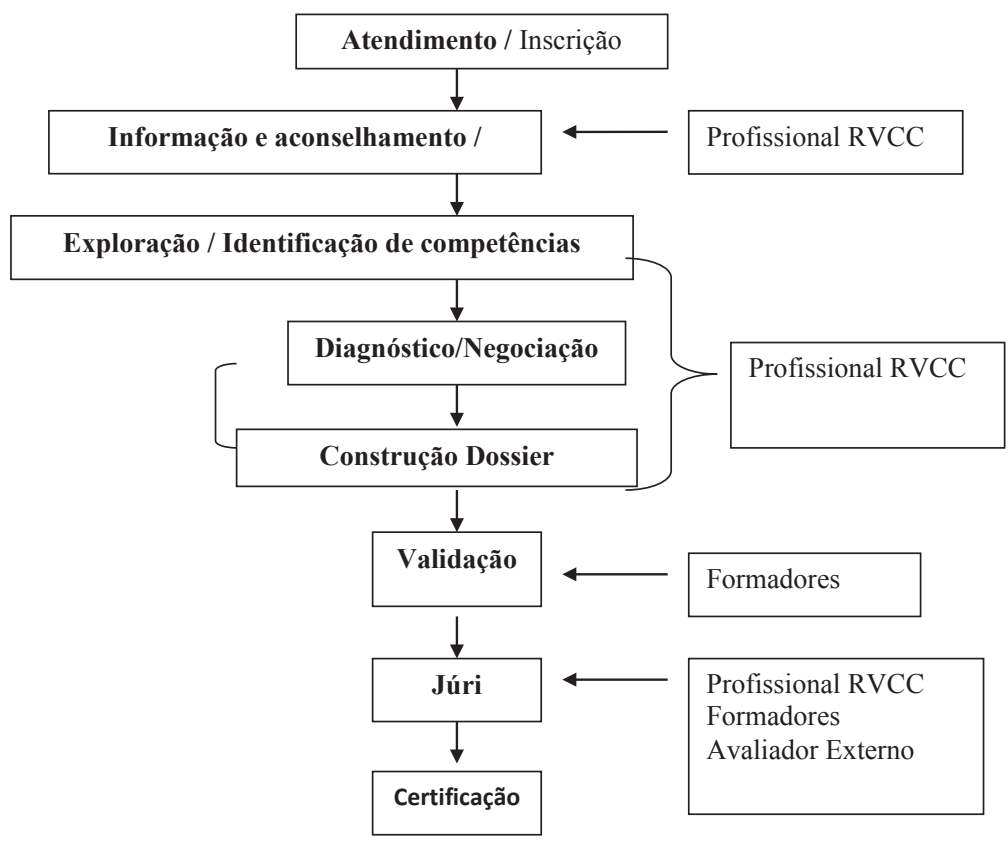

Esta oferta ao ter sido inscrita numa linha de enfrentamento do problema da subcertificação, suscitou nos discursos públicos o reconhecimento do potencial do processo RVCC para a "construção de oportunidades e percursos de formação congruentes com os trajetos e as aquisições passadas dos formandos" (Silva, 2002, p. 142), a par do reconhecimento da necessidade de se evitar que esta oferta se transformasse numa "atribuição administrativa de títulos escolares" (Silva, 2002, p. 142) motivada pela definição de metas físicas a atingir por cada CRVCC (neste período ainda confortáveis) em termos de certificação, para tornar este investimento eficaz no objetivo de contribuir para "recuperar, tão depressa quanto possível, o atraso acumulado" (Silva, 2002, p. 141).

Ora, após a extinção da ANEFA e a criação (Decreto - Lei n. ${ }^{\circ}$ 208/2002, DR 240, Série I-A, de 17 de Outubro) da Direção Geral de Formação Vocacional (DGFV), nasceu, neste âmbito, um modelo de gestão e avaliação de resultados imposto centralmente e destinado a ser operacionalizado perifericamente nas suas linhas mestras, com metas demasiado elevadas a cumprir, e do qual se fez depender diretamente a aprovação de financiamento, resultando num acréscimo substancial de trabalho burocrático, como revelam testemunhos recolhidos na época, como por exemplo este: 
...na prática, enquanto profissional de RVC, desenvolvo tarefas de natureza administrativa e educativa. Entre as tarefas administrativas destaco a elaboração de atas e de fichas de avaliação de desempenho, a realização do cronograma das sessões de trabalho com os adultos, o preenchimento de documentos vários alusivos ao processo de cada adulto (contrato, carteira pessoal de competências-chave, termos de posse, pedido de validação, diploma, entre outros), os sumários das sessões, o estabelecimento de contactos, a participação nas reuniões da equipa, a planificação das sessões individuais e de grupo, e a colaboração com os outros profissionais do Centro RVCC, nomeadamente no que se refere à produção de relatórios, de artigos, entre outros trabalhos solicitados à equipa [RE (S) 1. Trabalho de Campo 2004-2005]

Noutra direção, também Marques apontou duas variáveis que traduziam, à época, os problemas principais vividos pelos CRVCC desde que passaram a ser tutelados pela DGFV, nomeadamente: i) a variável do subfinanciamento; e ii) a variável que se prende com "a ausência de acompanhamento aos Centros por parte da tutela, o que se verifica desde 2003, e que tem como consequência podermos hoje afirmar que o sistema se encontra a funcionar em 'roda livre', sem qualquer controlo de qualidade de desempenhos e práticas" (Marques, 2007, p. 179). Também recolhemos inúmeros testemunhos que abordavam este problema, tal como este:

...em relação à DGFV há uma falta de acompanhamento e apoio aos Centros de RVCC (...) há mesmo uma falta de reconhecimento em relação ao nosso trabalho, muitas vezes, ou sempre, só reconhece as metas físicas, algo que na sua opinião reflete o bom ou mau desempenho do Centro. No ano de 2004, por exemplo, não houve acompanhamento ao nosso Centro [RE (A) 1. Trabalho de Campo 2004-2005]

Ora, as dificuldades sentidas no terreno por estas imposições ao Sistema EFA advindas da lógica de governação operacionalizada pela DGFV alertavam já os atores educacionais para a necessidade de encetar uma vigilância crítica para evitar que as novas ofertas de EFA se compartimentalizassem tornando-se meros dispositivos paliativos, que a ser assim, não serviriam o projeto de emancipação pessoal e social dos cidadãos em geral e dos mais desfavorecidos em particular contido na visão com que o Programa de Ação s@ber +, enquanto política pública, advogava. O risco era o de que as novas práticas de RVCC se transformassem em meros mecanismos renovados de confirmação das desigualdades sociais, e de eventuais percursos familiares de exclusão social e educacional, isto se o RVCC tende-se a ser usado para uma mera produção rápida de certificados escolares destinados aos adultos pouco escolarizados. 


\section{O RAE na Iniciativa Nova Oportunidades (2006-2012)}

Se o Programa s@ber + (1999-2005) ampliou e diversificou a oferta educacional pública disponível para os adultos portugueses já o Programa conhecido como INO, Iniciativa Novas Oportunidades (2006-2012), operou uma massificação (polémica em dispositivos de RAE) que alargou exponencialmente a rede de Centros em funcionamento no território nacional (rebatizados como Centros Novas Oportunidades, CNO) e estipulou metas de resultados (outputs) avassaladores para os atores envolvidos, expressando novas contradições e tensões nos mandatos atribuídos à EFA portuguesa e igualmente patente na mescla de elementos críticos e tecnocráticos presentes nos normativos do sector e nos discursos políticos associados. Com efeito, a INO desde logo apontou metas ambiciosas, quer para a criação de Centros, quer para o número de certificados. Foram anunciadas, em dezembro de 2005, metas concretas a atingir até 2010, pretendendo-se atingir a certificação-qualificação de cerca de 1.000.000 de adultos.

Com efeito, de acordo com dados fornecidos pela INO no Sistema de Informação e Gestāo da Oferta Educativa e Formativa (plataforma SIGO), referentes a dezembro de 2007, o total de adultos certificados que entre 2001 até 2005 havia sido de 59,040 (repartido entre os processos de RVCC num total de 44.253 e os Cursos EFA num total de 14.787) disparou para um total de 83.970, entre os anos de 2006 e 2007 (os processos de RVCC obtiveram um total de 76.922 e os Cursos EFA um total de 7.048).

Neste contexto, e não estando em causa o potencial do reconhecimento, validação, e mesmo certificação, dos adquiridos experienciais da população adulta, foram diversos os estudos que alertaram para um "pensamento 'mágico' ou administrativo que, por vezes, Ihe surge associado" (Rodrigues \& Nóvoa, 2005, p. 11), lembrando que se impunha quebrar com a lógica paliativa com que as ofertas de EFA passaram a ser concebidas, desde então, no contexto português "como se a menção 'ao longo da vida' nos dispensasse de uma adequada formação de base. Como se o 'reconhecimento dos adquiridos' pudesse assentar numa lógica administrativa, de uma 'certificação formal', sem uma verdadeira implicação da pessoa num processo de reflexão, de aprendizagem pessoal e de desenvolvimento profissional" (id., ibid., p. 12). Estes sinais de alerta permitiram questionar se o tipo de oferta pública de EFA e o Sistema de RVCC massificado serviria efetivamente a população portuguesa, ou se estaria inscrito na agenda das políticas educacionais, não para criar oportunidades significativas para a transformação e melhoria da vida dos coletivos populacionais, mas, apenas, como um expediente político de adequação nacional a um panorama internacional, isto no âmbito do novo paradigma das políticas para as estatísticas, para o qual neste sector o PIAAC (Programme for International Assessment of Adult Competencies) promovido 
pela Organização para a Cooperação e Desenvolvimento Económico (OCDE), tem vindo a dar um contributo assinalável.

O crescimento acelerado da Rede de CNO fez-se desde 2006 com base no Despacho $n^{\circ} 15$ 187, de 14 de julho, que determinava a abertura de centros aproveitando agora a própria rede escolar já existente, apontando as habilitações necessárias aos professores/formadores das áreas do Referencial de Competências-chave e atribuindo créditos horários às escolas onde funcionassem ofertas quer de cursos EFA quer de RVCC. O normativo reiterava as preocupações com a falta de certificação da população portuguesa e apontava a necessidade de colmatar essas lacunas através da rápida criação de mais CNOs. Nesta altura foi também criada a Agência Nacional para a Qualificação (ANQ) que veio substituir a DGFV (Decreto-lei n. ${ }^{\circ}$ 213/2006, de 27 de Outubro). Neste enquadramento os CNOs tinham como missão assegurar a educação e formação de jovens e adultos, prometendo resultados rápidos e eficazes, no sentido da melhoria das qualificações, sublinhando-se que estas eram preocupantemente inferiores às da média europeia. Os CNOs estiveram ainda associados a uma enorme divulgação, marketing e publicitação sem precedentes em Portugal, que, em definitivo, colocou a EFA na praça pública e popularizou o sector.

Acrescentou-se à lógica dos processos a possibilidade de conclusão do ensino secundário (a partir de 2007), também por via do RAE (até aqui dirigido apenas à conclusão da escolaridade básica). O Despacho n 11 203/2007, de 8 de Junho e a Portaria $n^{\circ} 370 / 2008$, de 21 de maio, determinaram os moldes em que se faria a expansão de funções nos CNOs e qual a nova composição da equipa: um diretor, um coordenador, um técnico de diagnóstico e encaminhamento, formadores, profissionais de RVC e técnicos administrativos.

Ora, os CNOs tinham, entre várias outras funções, as de assegurar o direito à educação dos adultos, encaminhando os candidatos para os Cursos EFA ou para o RVCC, visando a conclusão do ensino básico (nove anos de escolaridade) e também do ensino secundário (doze anos de escolaridade). Essas disposições tinham por base o já existente Referencial de Competências-Chave para o Ensino Básico, e o novo Referencial de Competências-Chave para o Ensino Secundário que apresentou novas áreas de competência ${ }^{2}$. Sendo que, no discurso público, verificou-se uma ênfase na importância das formações modulares como forma de conclusão do ensino secundário para candidatos (sobretudo jovens) com o ensino secundário incompleto, isto é, a quem faltasse até seis disciplinas para o concluir (Portaria n²30/2008, de 7 de março).

Não obstante a forte visibilidade pública que o campo da EFA adquiriu, totalmente inédito na sua história nacional, devido à agenda política da INO, e o aclamado sucesso medido pelo elevado número de centros e de candidatos certificados, esta medida foi alvo de diversas críticas, sendo a mais recorrente a que se prende com a elevada 
pressão que era exercida sobre os CNOs no sentido da obtenção das metas (Martins, 2014). O que, aliás, suscitou avisos originados em diversos quadrantes da sociedade portuguesa, dos quais destacamos o quadrante da academia, onde, entre outros exemplos, Nóvoa e Canário alertavam respetivamente, quer para a ideia de que "olhar para os RVCC como no passado se olhou para as 'campanhas de alfabetização', vendo-os como a solução mágica para resolver o 'atraso educacional português', seria a mais perigosa das ilusões" (Nóvoa, 2007, p. 12); quer de que "a justificação do programa retoma os habituais e 'velhos' clichés sobre a relação direta e linear entre o investimento na qualificação dos recursos humanos e o 'crescimento económico', o 'desenvolvimento', a 'superação do atraso', o 'emprego', a 'produtividade', a 'competitividade' e a 'coesão social'. Ora, não ficará mal reconhecer que esta relação direta não existe" (Canário, 2007, p. 167).

Várias foram as evidências que demonstraram que a INO representou um exemplo nacional de uma política para as estatísticas (Barros, 2018), baseada no que Brown diz ser uma "retórica inclusiva para uma realidade exclusiva" (Brown, 2000, p. 38), e que se disseminou uma retórica das oportunidades e da empregabilidade que contribuiu em larga medida para distribuir ilusões, dada a sua ocorrência num contexto de crescente crise estrutural motivada por um capitalismo globalizado cada vez mais predatório e implacável.

\section{A Suspensão do RAE (2013-2015) e o Advento do Programa Qualifica (2016)}

As alterações governativas que impuseram políticas de austeridade conduziram, neste âmbito, à extinção da rede de CNOs. Foram, porém, apresentados os Centros para a Qualificação e o Ensino Profissional (CQEP), que surgem em menor número e sem financiamento. Aparece também nova legislação afeta à regulação da organização dos CQEPs (Portaria n 135-A/2013 de 28 de março), que introduziu, desde logo, a redução do número de elementos constitutivos da equipa técnica (face ao modelo anterior dos CNOs). Assim, a figura do diretor foi extinta, o coordenador pedagógico deu lugar à figura de coordenador, os profissionais de RVC passaram a ser técnicos de Orientação, Reconhecimento e Validação de Competências (ORVC), os formadores mesmo vistos como necessários, passaram a ser em menor número (ficando à mercê das disponibilidades dos professores das escolas). Neste particular, é de referir que quando os centros estavam instalados em escolas, no modelo CNOs, a disponibilidade dos professores destacados era total na maior parte dos casos, nos CQEPs, cada professor, independentemente do cargo ocupado no centro, passou a dispor de uma carga horária limitada, sendo o seu restante horário constituído por turmas do ensino 
regular. Tratava-se de uma relação entre CQEP e escola em que o centro ficou a perder, como referem estes testemunhos,

(...) O CQEP era um bocadinho... um parente pobre da Escola... (E1. Trabalho de Campo 2017)

E há outra desvantagem... é que, se a pessoa estiver única e exclusivamente como formadora de um Centro, terá mais disponibilidade, pronto, estará mais concentrada apenas no Centro. Aqui nós acabamos por ter que nos dividir... (E1. Trabalho de Campo 2017)

Não obstante, em termos de fases do processo de RVCC os novos CQEPs herdaram os passos necessários para acompanhar os candidatos desde o acolhimento, o diagnóstico, a informação e orientação e o encaminhamento, não herdando, porém, a mesma dimensão da equipa, o que nas palavras de uma técnica significou:

Como tínhamos pessoal limitado, como técnicas fazíamos tudo... desde o acolhimento do adulto, a sua inscrição e depois as diferentes fases. A parte de informação, de diagnóstico, até ao encaminhamento. Sempre, fazíamos tudo. Inclusivamente, até fazíamos a seguir, depois dos processos RVCC, fazíamos também a formação. Nós fizemos tudo (E2. Trabalho de Campo 2017)

Ainda no âmbito do processo RVCC, merece destaque a inovação, que foi introduzida pela nova agenda política, do surgimento de uma prova, com o valor de $60 \%$ da totalidade do processo, nas modalidades escrita e oral. Esta caraterística, nova em Portugal no âmbito do processo de RAE, apareceu justificada no discurso público como uma pretensão de atribuir mais rigor ao processo, dando-Ihe agora uma dimensão escolar. Ora, como temos comprovado, no âmbito da investigação-ação em curso, a questão da elaboração da prova, da responsabilidade das equipas dos CQEPs, suscitou controvérsia e debate, já que as provas de cada área de competência tinham de contemplar todos os temas (no caso do RVCC básico) ou todos os domínios de referência (no caso do RVCC de nível secundário). Esta lógica, só por si mesma, originaria uma prova demasiado longa, criando-se assim um problema, de resto inusitado no âmbito dos princípios pedagógicos inerentes à EFA. A resposta avançada, por parte de alguns centros, passou pela construção de provas com questões de desenvolvimento intercaladas com outras de resposta curta ou de escolha múltipla. Sendo que, nas questões de desenvolvimento eram oferecidas várias possibilidades, com o propósito de conferir maior abertura à ideia de fazer uma prova incentivando, em simultâneo, os 
candidatos a integrar as suas experiências de vida nas temáticas indagadas segundo os diversos núcleos geradores das áreas de competência-chave.

Em suma, o que se destaca entre 2013 e 2015, basicamente, é uma ação política nacional impositiva, através da qual se fragilizou substantivamente as práticas de RAE em Portugal, dado que se reduziu a dimensão da rede de centros anteriormente criada, se minimizou a dimensão das equipas, se retirou $60 \%$ de valor ao portfólio construído com base em metodologias de proximidade, como as abordagens biográficas e o balanço de competências, e se abandonou o financiamento aos centros. Ou seja, dito por outras palavras, sob uma ação política justificada por um discurso público de crise e austeridade, de legitimação externa, a EFA em Portugal desapareceu da agenda política até ao advento do Programa Qualifica. Efetivamente, com as alterações governativas de finais de 2015, emerge a terceira e mais recente política para a EFA em contexto nacional, no âmbito da qual foram criados os Centros Qualifica (CQ) que passaram a substituir os anteriores CQEPs (Portaria 232/2016 de 29 de agosto, e Despacho 1971 de 8/3/2017).

Ora, é importante referir que, entre outros aspetos, o Governo em funções herdou a crise de legitimidade das severas medidas neoliberais de ajustamento da sociedade e do Estado quer às demandas supranacionais quer aos agentes financeiros nacionais, que têm vindo a pressionar visivelmente a macroestrutura no sentido da privatização dos lucros e da socialização dos prejuízos. Não sendo expectável que a ação governativa fosse suspender a política de austeridade, verificou-se, no entanto, um reconhecimento subtil, no novo discurso público, de que há alternativas contrárias ao empobrecimento dos Estados e das populações, e que se pode dar um uso menos ortodoxo à margem (estreita) de manobra que uma certa soberania nacional ainda permite.

Assim, e em contraciclo com as medidas anteriores, verifica-se que "o Governo estabeleceu como prioridade política de âmbito nacional a revitalização da educação e formação de adultos, enquanto pilar central do sistema de qualificações, assegurando a continuidade das políticas de aprendizagem ao longo da vida e a permanente melhoria da qualidade dos processos e resultados de aprendizagem" (Programa Qualifica, 2017, s/p). Ora, as principais inovações introduzidas nos novos CQ foram, por um lado, o alargamento das equipas, com a contratação de dois Técnicos de ORVC, autorizada em outubro de 2016, os quais, não sendo professores, dedicam todo o trabalho ao centro, possibilitando assim outra dinâmica nos atendimentos, encaminhamentos e processos de RVCC; e por outro lado, o maior tempo que as várias fases do processo, nomeadamente: o acolhimento, o disgnóstico, a informação e orientação e o encaminhamento passaram a dispor, sendo agora as equipas, a partir de março de 2017 , compostas do seguinte modo: um coordenador, dois Técnicos de ORVC e vários formadores, todos professores e com parte dos seus horários preenchidos com turmas do ensino regular. Estas equipas passaram a ter dispositivos de apoio novos, que se 
enquadram em orientações muito práticas para o processo RVCC, e que aparecem propostas em dois documentos: i) o Guia Metodológico; e ii) a Orientação Metodológica N. ${ }^{\circ}$ (ANQEP, 2017a; 2017b). Criou-se também o Passaporte Qualifica, documento a que se acede através da plataforma SIGO, onde são registadas todas formações validadas dos candidatos.

Porém, a alteração mais notória, face ao modelo anterior surge precisamente no âmbito da prova, que nos atuais processos RVCC continua como obrigatória, mas deixou de ser escrita, passando a ser uma apresentação oral perante um júri de certificação, no fundo retomando-se assim, no essencial, a lógica do júri de validação existente no período de vigência dos CRVCC (mas sem a figura do avaliador externo). A Orientação Metodológica N. ${ }^{\circ} 1$ aponta três momentos nesse processo, designadamente: i) o da preparação para a prova, que poderá decorrer até 25 horas; ii) o momento do Júri de Certificação, que agora se designa como prova; e finalmente, iii) um terceiro momento a que chama avaliação e tomada de decisão. A importância da prova continua a ser significativa, sendo considerada como o remate final do trabalho do candidato, cuja preparação é acompanhada pela equipa, sobretudo pelos Técnicos de ORVC e pelos formadores. Neste particular, as diferenças, face ao modelo anterior, são significativas dado que nem a prova tem avaliação quantitativa nem é escrita.

Há ainda a destacar o aspeto da formação complementar aos candidatos RVCC que nos CQEPs podia atingir 25 horas e que se apresenta agora nos CQ como um imperativo, sendo no mínimo de 50 horas. A questão é apresentada ao nível do Programa Qualifica como destinada a possibilitar a formação nas áreas em que o candidato apresente menos competências. Não obstante, não é uma opção isenta de problemas para os CQ, dado que, se por um lado, vem representar um acréscimo de dificuldades na elaboração de grupos e horários para formação presencial; por outro lado, evidencia o paradoxo resultante da manutenção do não financiamento destes $C Q$, enquanto os cursos para a formação complementar, que são assegurados por entidades privadas (oferecidas para os CQ sob a forma de protocolos) beneficiam de financiamento. São aspetos presentes nos testemunhos que recolhemos,

Sim, duplicou. Sim, sim, sim. Pronto, torna-se complicado para algumas pessoas, porquê, porque pretendendo-se fazer sessões em grupo, hum... seguranças têm horários rotativos, supermercados, rotativos, hospitais, rotativos... portanto, é muito difícil arranjar horários em que as pessoas possam vir... (...) Mas há esse problema, há. Acho que são muitas horas... há pessoas que podem necessitar dessas 50 horas de facto. Mas há outras que não necessitam... (E1. Trabalho de Campo 2017) 
É ainda interessante notar que o processo de RVCC, em termos gerais, é percecionado pelos elementos da equipa técnica, como adequado e não aportando dificuldades especiais aos adultos pouco escolarizados, sendo referido que a maior dificuldade, desde a origem do RAE em Portugal se relacionou sempre com a 'tradução' dos referenciais. Porém é apontado que esta questão beneficia já de um vasto património de resposta, constituído de materiais de desconstrução da complexidade inerente aos dois referenciais existentes em Portugal (inalterados desde a sua criação). Uma das técnicas refere a este respeito o seguinte,

Nós olhávamos para o referencial e dizíamos, mas o que é isto, isto é... é extremamente complexo (...) Daí que começou... todos os centros começaram a desconstruir o referencial e a arranjar uns documentos próprios, hum... dando sugestões... (E2. Trabalho de Campo 2017)

Por fim há o facto contraditório, que merecerá um maior estudo da nossa parte, de o processo de RVCC ser percecionado, pelas comunidades de práticas, como adequado aos adultos pouco escolarizados, ao mesmo tempo que os dados existentes na plataforma SIGO atestam uma taxa de desistência e abandono bastante significativa. Haverá, pois, que investigar mais aprofundadamente este aspeto, sendo que nos interrogámos desde logo, a este propósito, se o facto da agenda educacional para este sector em Portugal estar caraterizada pela inconsistência, não contribuirá para desmotivar adultos pouco escolarizados, com experiencias pouco positivas da escola, impedindo-os de iniciarem, e manterem, processos de RAE que, não obstante a sua dedicação, correm riscos reais de serem abruptamente interrompidos, como, de resto sucedeu recentemente no nosso país. Se é certo que o cenário político nacional, no presente momento, comporta sinais de mudanças em prol dos direitos sociais, com um reflexo positivo no sector da EFA, não deixa, igualmente, de ser certo que a dimensão estrutural dessas mudanças, e a consequente capacidade da sua manutenção no tempo, se encontram em aberto, pelo que estarão, seguramente, sob a nossa observação atenta.

\section{Considerações finais}

Este artigo percorre o desenvolvimento nacional da EFA, desde a criação, em 1999, do Projeto de Sociedade S@ber +, que constitui o marco político a partir do qual emerge, em 2001, uma agenda de EFA assente no RAE em Portugal. Este Projeto suscitou um conjunto sequencial de três políticas públicas destinadas à educação das pessoas adultas, designadamente: o Programa de Ação S@ber+: Programa para o Desenvolvimento e Expansão da Educação e Formação de Adultos (1999-2005), o Programa 
Iniciativa Novas Oportunidades (2006-2012) e o Programa Qualifica (desde 2016), cujo denominador comum é estarem alicerçadas em práticas de RAE.

Com quinze anos de história, o RVCC português sofreu diversas transformações que este texto procurou analisar nos aspetos essenciais, permitindo argumentar que o RAE representa uma prática incontornável, não obstante as tensões mapeadas neste texto, para a promoção de equidade e igualdade no usufruto do direito à educação por parte dos adultos pouco escolarizados, que em Portugal têm sido os beneficiários prioritários desta agenda educacional.

\section{Notas}

1 No Referencial de Competências-chave do Ensino Básico, as áreas eram e ainda são: Cidadania e Empregabilidade (CE), Linguagem e Comunicação (LC), Matemática para a Vida (MV) e Tecnologias de Informação e Comunicação (TIC). Ver: ANEFA (2002). Referencial de Competências-chave para a Educação e Formação de Adultos (nível básico). Lisboa: ANEFA. Disponível em: http:// www.anqep.gov.pt/default.aspx

2 No Referencial de Competências-chave do secundário, as áreas são: Cidadania e Profissionalidade (CP), Cultura, Língua e Comunicação (CLC) e Sociedade, Tecnologia e Ciência (STC). Ver: DGFV (2006). Referencial de Competências-chave para a Educação e Formação de Adultos (nível secundário). Lisboa: ME/DGFV. Disponível em: http://www.anqep.gov.pt/default.aspx

\section{Referencias Bibliográficas}

Andersson, P., Fejes, A., \& Sandberg; F. (Eds). (2016). Recognition of Prior Learning - Research from around the globe. London: Routledge.

ANEFA (2001). Relatório de atividades 2000. Lisboa: ANEFA.

ANEFA (2002). Centros de Reconhecimento, Validação e Certificação de Competências - Roteiro Estruturante. Lisboa: ANEFA.

ANQEP. (2017a). Orientação ao Longo da Vida nos Centros Qualifica - Guia Metodológico. Lisboa: ANQEP.

ANQEP. (2017b). Reconhecimento, Validação e Certificação de Competências Escolares (RVCC Escolar) - Orientação Metodológica N. ${ }^{\circ}$ 1. Lisboa: ANQEP.

Barros, R. (2018). The Role of Transnational Bodies in Lifelong Learning and the Politics of Measurement - The global promise and national pitfalls of outcomes-based assessment into RPL System in Portugal. In Finnegan, F. \& Grummell, B. (Eds). Power and Possibility: Adult Education in a Diverse and Complex World. Rotterdam: Sense Publishers. [forthcoming].

Barros, R. (2014). The Portuguese recognition of prior learning (RPL) policy agenda: Examining a volatile panacea by means of ethno-phenomenological interpretations. Encyclopaideia, Journal of Phenomenology and Education, XVIII(40),53-68.

Barros, R. (2013a). O Movimento das Histórias de Vida e a Educação de Adultos de Matriz Crítica: Ideias e Conceitos em Contexto, Revista Lusófona de Educação, 23, 31-50.

Barros, R, (2013b). The Portuguese case of RPL new practices and new adult educators - some tensions and ambivalences in the framework of new public policies. IJLE - International Journal of Lifelong 
Education - Special issue title: Researching recognition of prior learning around the globe, Vol. 32, Iss.4, 430-446.

Barros, R. (2011). A Criação do Reconhecimento de Adquiridos Experienciais (RVCC) em Portugal Uma Etnografia Crítica em Educação de Adultos. Lisboa: Chiado Editora.

Barros, R. (2009). Políticas para a educação de adultos em Portugal: A governação pluriescalar da «Nova Educação e Formação de Adultos» (1996-2006). Volume I e II. (Tese de doutoramento não publicada). Universidade do Minho, Braga.

Brown, U. (2000). Inclusive Rhetoric, Exclusive Reality. In Jane Thompson \& Mae Shaw \& Liam Bane (Ed.). Reclaiming Common Purpose (pp. 38-41). Nottingham: NIACE.

Canário, R. (2007). Multiplicar as Oportunidades Educativas. In CNE. Aprendizagem ao Longo da Vida no Debate Nacional sobre Educação. Lisboa: Conselho Nacional de Educação.

CNE (2002). Aprendizagem ao Longo da Vida (Parecer $n^{\circ}$ 1/01, redigido por A. Rita Varela). In CNE, Pareceres e Recomendações, 2001 (pp. 15-136). Lisboa: Conselho Nacional de Educação / Ministério da Educação.

Correia, A. \& Cabete, D. (2002). O valor do que Aprendemos ao Longo da nossa Vida... e a Importância do Sistema Português de RVCC. In Melo e Silva, I.; Leitão, J. A.. e Trigo. M. M. (org.). Educação e Formação de Adultos - Factor de Desenvolvimento, Inovação e Competitividade (pp. 45-53). Lisboa: ANEFA.

Marques, F. (2007). Centros RVCC: Análise da Situação e Propostas. In Conselho Nacional de Educação, Aprendizagem ao Longo da Vida no Debate Nacional de Educação (pp. 177-184). Lisboa: CNE/ Ministério da Educação.

Martins, J. (2014). Das políticas às práticas de educação de adultos. Lisboa: Edições Colibri.

Melo, A., Matos, L., \& Silva, O. S. (2001). S@ber+: Programa para o desenvolvimento e expansão da educação e formação de adultos, 1999-2006. Lisboa: ANEFA/GMEFA.

Nóvoa, A. (2007). É Preciso Manter uma Vigilância Crítica sobre o Reconhecimento de Adquiridos Entrevista a António Nóvoa. In Aprender ao Longo da Vida, 7, 10-18.

Pires, A. L. (2005). O Reconhecimento e a Validação das Aprendizagens dos Adultos: Contributos para a Reflexão Educativa. Disponível em https://comum.rcaap.pt/

Programa Qualifica (2017). Programa Qualifica. Consultado em: https://www.qualifica.gov.pt/\#/ programaQualifica

Rodrigues, C., Nóvoa, A. (2005). Prefácio. In Rui Canário; Belmiro Cabrito (org.). Educação e Formação de Adultos - Mutações e Convergências (pp. 7-14). Lisboa: EDUCA-Formação.

Silva, A. S. (2002). Por uma política de ideias em educação. Porto: Edições ASA. 
Barros: Emergência e transformações ocorridas nas políticas e práticas de reconhecimento de adquiridos experienciais (RAE) em Portugal (1999-2017)

doutoramento em educação pela Universidade do Minho sendo Professora Adjunta na Universidade do Algarve. Desde 2017, é associate convenor of the Research Network on Policy Studies in Adult Education of ESREA (https://www.esrea.org/networks/policy-studies-in-adult-education/). Tem diversos projetos de investigação com financiamento nacional e internacional. Tem publicado vários livros, capítulos e artigos ORCID: http://orcid.org/0000-0002-3882-1539.

Contacto: rmbarros@ualg.pt

Data de Submissão: Septembro 2017 Data de Avaliação: Dezembro 2017 Data de Publicação: Septembro 2018 